\title{
Investigation of Fasting Ratio of C-Peptide/Glucose and Related Markers in Diabetes Hiroshi BANDO ${ }^{* 1,2}$, Koji EBE ${ }^{2,3}$, Tetsuo MUNETA ${ }^{2,4}$, Masahiro BANDO ${ }^{5}$, Yoshikazu YONEI ${ }^{6}$ \\ ${ }^{* 1}$ Tokushima University / Medical Research, Tokushima, Japan. ${ }^{2} J a p a n$ Low Carbohydrate Diet Promotion Association, Kyoto, Japan. \\ ${ }^{3}$ Takao Hospital, Kyoto, Japan. \\ ${ }^{4}$ Muneta Maternity Clinic, Chiba, Japan. \\ ${ }^{5}$ Department of Nutrition and Metabolism, Institute of Biomedical Sciences, Tokushima University Graduate School, Tokushima, Japan. \\ ${ }^{6}$ Anti-Aging Medical Research Center, Graduate School of Life and Medical Sciences, Doshisha University, Kyoto, Japan. pianomed@bronze.ocn.ne.jp; koji.ebe@gmail.com; czf06641@nifty.com; b_moppy@hotmail.com; yyonei@mail.doshisha.ac.jp \\ *Corresponding Author: Dr. Hiroshi BANDO, Tokushima University / Medical Research, Tokushima, Japan.
}

Abstract

Background: Authors have continued research concerning Low Carbohydrate Diet (LCD) and its related biomarkers. We also investigated correlation among several factors such as daily profile, fasting and average of blood glucose, Morbus value, and insulin and C-peptide.

Subjects and Methods: Subjects were patients with type 2 diabetes mellitus (T2DM), classified into three groups due to HbA1c value. Methods included 1) basal blood exams, 2) intake of Calorie Restriction (CR) meal with $1400 \mathrm{kcal} /$ day with $60 \%$ of carbohydrates, 3) check of daily blood glucose 7 times a day, 4) calculation of average glucose and $M$ value, 5) analyses of biomarkers.

Results: Average blood glucose was $168 \mathrm{mg} / \mathrm{dL}, 206 \mathrm{mg} / \mathrm{dL}, 265 \mathrm{mg} / \mathrm{dL}$ in low, middle, high group, respectively. Fasting ratio of C-peptide/glucose in 3 groups was 0.37, 0.34, 0.26, respectively period. There was significant correlation among $\mathrm{HbA1c}, M$ value and fasting ratio of C-peptide/glucose.

Discussion and Conclusion: Among 3 groups, high group revealed lower tendency of fasting C-peptide and fasting ratio of C-peptide/glucose than other groups, suggesting that high group might has lower ability of insulin secretion. Fasting ratio of C-peptide/glucose would be useful for indicating beta cell function and predicting insulin requirement in clinical practice.

Keywords: Fasting ratio of C-peptide/glucose; Calorie Restriction (CR); C-peptide (CP); type 2 diabetes mellitus (T2DM); C-peptide index (CPI).

\section{AbBreviation}

CR: Calorie Restriction

LCD: low carbohydrate diet

T2DM: type 2 diabetes mellitus

$M$ value: Morbus value

MAGE: mean amplitude of glycemic excursions

75gOGTT: $75 \mathrm{~g}$ oral glucose tolerance test

MTT: meal tolerance test

CPI: C-peptide index

\section{INTRODUCTION}

In recent decades, there have been various nutrition and metabolic problems in developing and developed countries. Metabolic syndrome (Met-S) such as obesity and diabetes has increased, which was formerly called syndrome X. [1]. It has become inevitable medical and social issues to be resolved $[2,3]$. There are lots of factors to be influenced by country, meal habit, lifestyle, age, exercise, economic situation, and so on. Diabetes has been increasing rapidly in the world. It 
Investigation of Fasting Ratio of C-Peptide/Glucose and Related Markers in Diabetes

has a variety of complications with macro- and microangiopathy including large vessels of head, heart, leg and neuropathy, retinopathy and neuropahy [4]. Consequently, several guidelines for treating diabetes has been presented for better management in the countries $[5,6]$. International Diabetes Federation (IDF) proposed the Standards of Medical Care, in which evaluating the intake and counting amount for carbohydrate with experience-based calculation would be emphasized [7]. Recent discussion has been focused in the recommended HbA1c level in various situations, especially between American Diabetes Association (ADA) and American College of Physicians (ACP) $[8,9]$.

On the other hand, we have observed the continuing discussion about the ideal nutrition treatment for diabetes. They include the comparison between Low Carbohydrate Diet (LCD) and Calorie restriction (CR) diet by many researchers. LCD was begun by Bernstein and others, which was wide spread after that in western countries [10]. Consecutively, there were lots of reports for beneficial effects of LCD compared with CR [11-13].

In Japan, author and colleagues have started and continued clinical research concerning LCD [14]. We proposed actually simple and useful LCD formula including super, standard and petit LCD, which can be applicable to every occasion [15]. Moreover, we have investigated some reports in relation to hypercholesterolemia, renal function, ketone bodies and actually simple and useful LCD formula including super, standard and petit LCD [16-18]. Furthermore, we have developed social movement through the activity of Japan Low Carbohydrate Diet Promotion Association.

As mentioned above, we have continued clinical research about diabetes, CR and LCD. Our research protocol has breakfast of CR with $70 \mathrm{~g}$ of carbohydrate. Through our research program, we have proposed breakfast similar to $75 \mathrm{~g}$ of glucose tolerance test. Pancreatic function can be speculated by the response of insulin and blood glucose [19]. In order to develop this research, we investigated fasting ratio of $\mathrm{C}$-peptide and blood glucose, as well as fasting and average blood glucose and Morbus (M) value calculated for a day in this study.

\section{SubJects AND Methods}

In current study, we enrolled patients with type 2 diabetes mellitus (T2DM). They were admitted for further evaluation and treatment for T2DM. According to the value of $\mathrm{HbA1c}$, they were classified into three groups which was low, middle, high, respectively. The account number of the cases in each group was 15,15 , 16 , respectively.

Methods are from our usual procotol for diabetic investigation. It includes providing Calorie Restriction (CR) diet on Day 1 and 2, and changing into Low Carbohydrate Diet (LCD) after day 3.

In current study, a series of procedure was as follows: 1) On the morning of Day 2, we have measured basal biomarkers concerning diabetes after overnight fast, including blood glucose and C-peptide (CP). Blood samples were drawn before breakfast, after the patient was keeping still more than 15 minutes. 2) After taking blood samples, breakfast was given to the subjects, which was includes protein PFC ratio (protein 15\%, fat $25 \%$, carbohydrate $60 \%$ ) with $1400 \mathrm{kcal} /$ day. As to breakfast, carbohydrate amount is $70 \mathrm{~g}$. This is along to the standard nutrition guideline in Japan, proposed from Japan Diabetes Society (JDS) [20].

\section{Formula of C-Peptide and M Value}

The formula of Fasting ratio of C-peptide/glucose is defined as $100 \mathrm{x}$ fasting $\mathrm{C}$-peptide value / fasting glucose. Blood sample was obtained on the morning of Day 2 after overnight fast.

As to the glucose variability, we checked the daily profile of blood glucose on day 2 for 7 times a day. The time was 0800, 1000, 1200, 1400, 1700, 1900, 2200h. According to these data, average blood glucose in a day on Day 2 and also M value were calculated.

$M$ value is one of the biomarker which indicates average blood glucose level and also the mean amplitude of glycemic excursions (MAGE)[21,22]. M value can indicate average and swinging degree of blood glucose. It can be calculated for a logarithmic transformation of the deviation of glucose from ideal glucose value[21-23].

Detail of $M$ value is in the following. At first, $M=M^{B S}$ $+\mathrm{M}^{\mathrm{W}}$ : M value is the total of $\mathrm{M}^{\mathrm{BS}}$ and $\mathrm{M}^{\mathrm{W}}$. Secondly, $\mathrm{M}^{\mathrm{W}}$ is maximum blood glucose - minimum glucose)/20. Thirdly, $\mathrm{M}^{\mathrm{BS}}$ is the mean of MBSBS. Finally, MBSBS is the individual $\mathrm{M}$-value for each blood glucose, 
Investigation of Fasting Ratio of C-Peptide/Glucose and Related Markers in Diabetes

calculated as (absolute value of $[10 \times \log$ (blood glucose level/120)] $)^{3}[20-22]$.

The evaluation for the $\mathrm{M}$ value reveals that normal is less than 180 , borderline is from 180 to 320 , abnormal level is more than 320 . From the experimental research, there are similar results in the case of sampling of 7 times or 20 times a day. Furthermore, obtained data would be compatible with that of continuous glucose monitoring (CGM) [22-24].

\section{Statistical Analysis}

In current study, data were represented by the median and quartile of $25 \%$ and $75 \%$ according to the biomarkers. It is described as median [25\% $75 \%$ ]. Statistical investigation involved the usage of correlation coefficients, according to the Spearman test. The reference method was used on the analytical evaluation [25].

\section{Ethical Standard}

This research was conducted in compliance with the ethical principles based upon the Declaration of Helsinki. Moreover, additional commentary was done in 2004 General Assembly Tokyo, Japan. It was conducted with Personal Information Protection Law and in reference to "Standards for the Implementation of Clinical Trials (GCP), an ordinance of the Ministry of Health, Labour and Welfare No. 28 of March 27, 1997. There was also "Ethical Guidelines for Epidemiology Research" by the Ministry of Education, Culture,
Sports, Science and Technology and the Ministry of Health, Labour and Welfare.

Authors had an ethical committee that includes doctor, nurse, pharmacist and expert in the legal specialty. We have discussed and confirmed that current study is valid and agreed with all members. In addition, informed consents and written paper agreements have been obtained from the subjects. This investigation has been registered in the open database (UMIN) by National University Hospital Council of Japan (ID: \#R000031211).

\section{RESULTS}

\section{Fundamental Data}

There were fundamental data in three groups, which were revealed in Table 1 . Among these, there are similar ages in 3 groups, and the median $\mathrm{HbA1c}$ was $6.8 \%, 7.9 \%, 9.7 \%$, respectively. Average blood glucose and $M$ value showed increasing level in the order of group 1 to 3 , in which the difference of numerical value is larger in $\mathrm{M}$ value than that in glucose.

\section{Fasting Glucose}

Fasting level of blood glucose in 3 groups are shown in Fig.1. In the 3 groups, median value was $138 \mathrm{mg} /$ $\mathrm{dL}, 157 \mathrm{mg} / \mathrm{dL}, 146 \mathrm{mg} / \mathrm{dL}$, respectively, which was not increased in low, middle, high group (Fig.1). On contrast, average value was $168 \mathrm{mg} / \mathrm{dL}, 206 \mathrm{mg} / \mathrm{dL}$, $265 \mathrm{mg} / \mathrm{dL}$, respectively, which was increased in the order of group 1 to 3 (Table 1 ).

Table 1. Subjects and basal data

\begin{tabular}{|l|c|c|c|}
\hline & Group 1 & Group 2 & Group 3 \\
\hline Subjects & & & \\
age(median [25\%-75\%] & $37[60-68.5]$ & $62[52-71.5]$ & $65[61-68.5]$ \\
age(min-max) & {$[35-75]$} & {$[47-79]$} & {$[41-80]$} \\
count(number) & 15 & 15 & 16 \\
\hline Glucose profile & & & \\
HbA 1 c (\%) & $6.8[6.4-7.1]$ & $7.9[7.6-8.0]$ & $9.7[9.2-10.0]$ \\
average glucose (mg/dl) & $168[149-174]$ & $206[166-214]$ & $265[177-282]$ \\
Morbus value & $51[40-61]$ & $130[62-156]$ & $326[57-422]$ \\
\hline
\end{tabular}

\section{Fasting C-peptide}

Fasting value of C-peptide in 3 groups are shown in Fig.2. In the 3 groups, median value was $0.9 \mathrm{ng} / \mathrm{mL}$, $0.9 \mathrm{ng} / \mathrm{mL}, 0.75 \mathrm{ng} / \mathrm{mL}$, respectively. There are similar value between group 1 and 2 .

\section{Fasting Ratio of C-Peptide/Glucose}

The data of the fasting ratio of C-peptide/glucose in 3 groups are shown in Fig.3. The value was in 3 groups was $0.37,0.34,0.26$, respectively, which is decreasing in the order of group 1 to 3 . This ratio is involved in glucose (Fig.1) and C-peptide (Fig.2). 


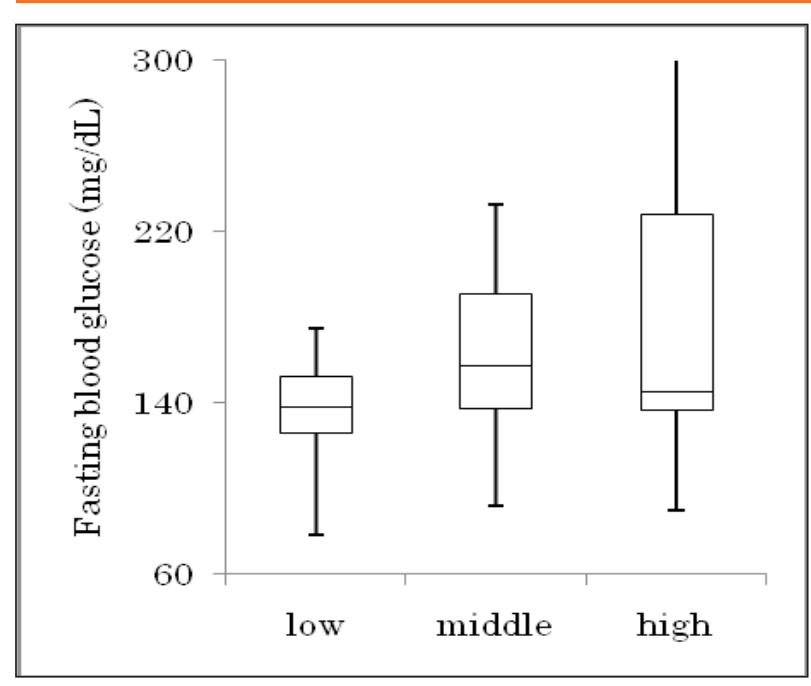

Figure 1. Fasting level of blood glucose in 3 groups

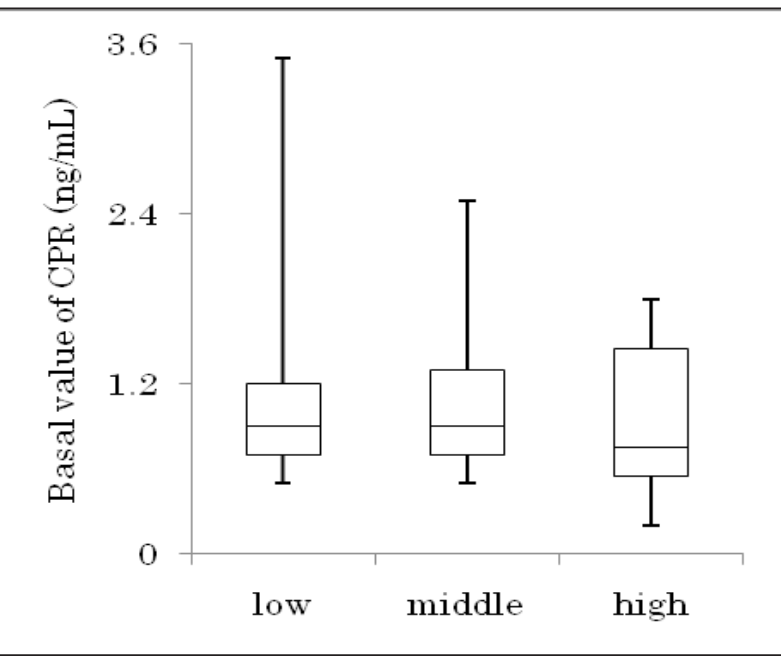

Figure 2. Fasting value of C-peptide in 3 groups.

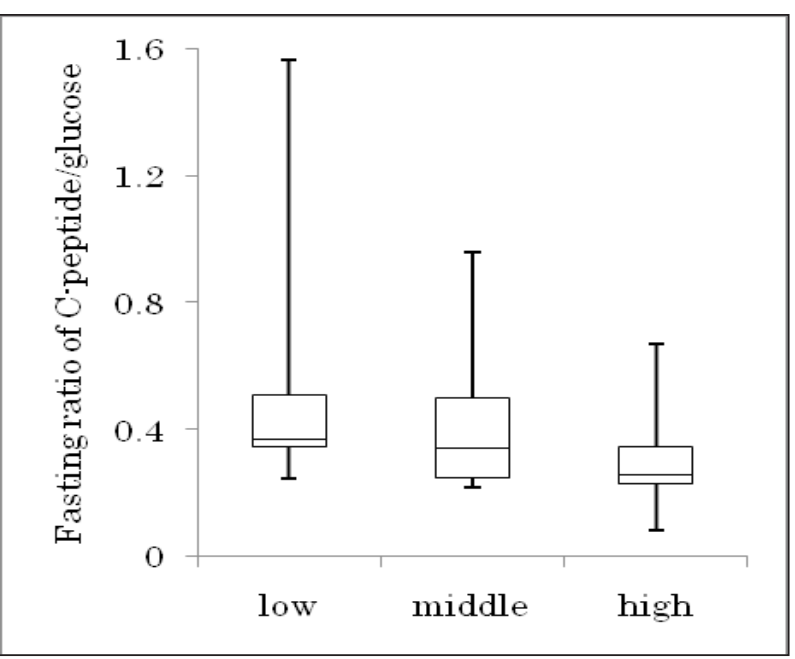

Figure 3. Fasting ratio of C-peptide/glucose in 3 groups
Correlation among HbA1c, M Value and Ratio of CP/Glucose

There was significant negative correlation between HbA1c and fasting ratio of $\mathrm{CP} /$ glucose $(\mathrm{p}<0.05)$ (Fig.4). Similarly, there was significant negative correlation between $\mathrm{M}$ value and fasting ratio of $\mathrm{CP} /$ glucose $(\mathrm{p}<0.05)$ (Fig.5). On contrast, there was not significant correlation between average blood glucose and fasting ratio of $\mathrm{CP} /$ glucose (Fig.6).

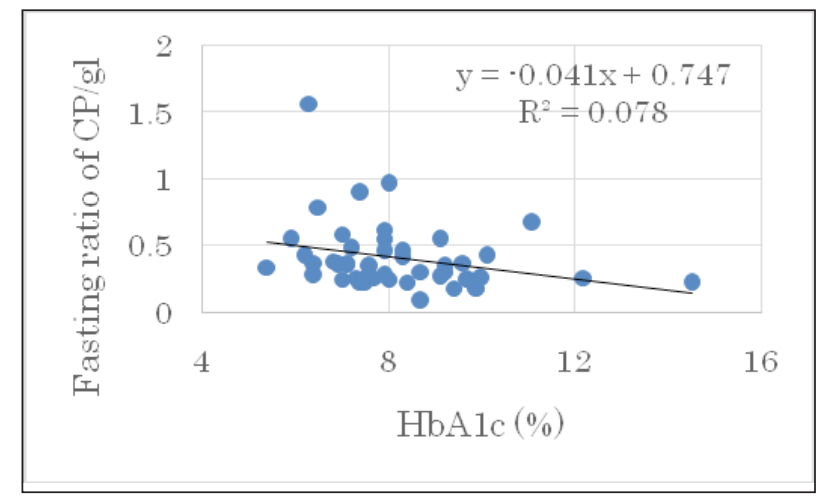

Figure 4. Correlation between $\mathrm{HbA1c}$ and Fasting ratio of $\mathrm{CP} /$ glucose

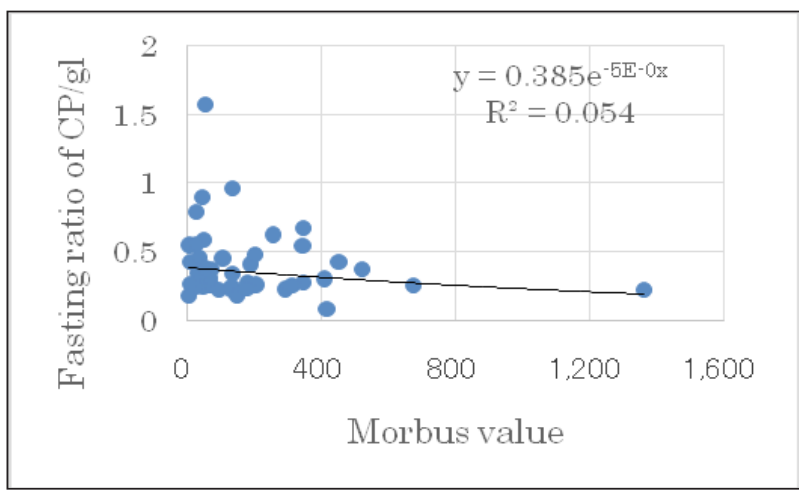

Figure 5. Correlation between $M$ value and Fasting ratio of $\mathrm{CP} /$ glucose

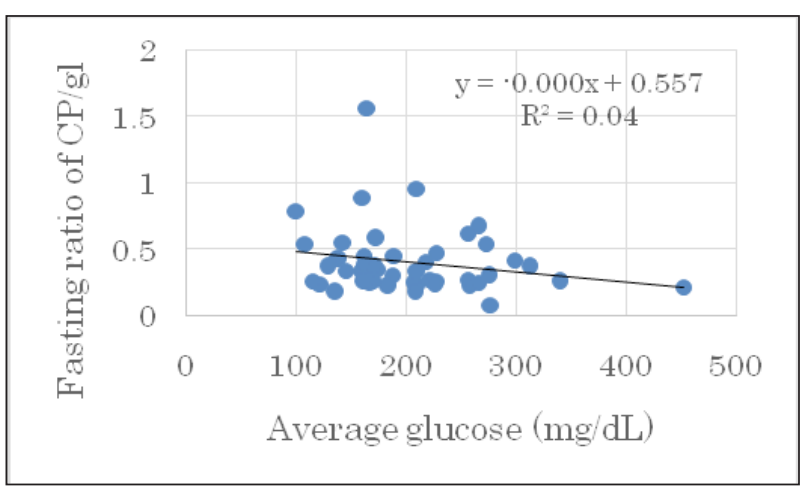

Figure 6. Correlation between Average glucose and Fasting ratio of CP/glucose 
Investigation of Fasting Ratio of C-Peptide/Glucose and Related Markers in Diabetes

\section{DISCUSSION}

Research on CR and LCD on diabetes diet therapy has advanced in the world with the accumulation of lots of evidence. In this field, authors have been continuing our research in two axes.

The first axis is a comparison between two types of meals, CR and LCD. Blood glucose profile, mean blood glucose level, blood glucose fluctuation, urinary $\mathrm{CP}$ excretion are different between both groups [26]. Furthermore, the $\mathrm{M}$ value indicating both the mean blood glucose and the blood glucose fluctuation has been useful for clinical research [27].

As the second axis, we examined the variation of blood glucose, insulin and C-peptide for breakfast intake containing a certain amount of carbohydrate [19]. Conventionally, $75 \mathrm{~g}$ oral glucose tolerance test $75 \mathrm{~g}$ OGTT) has been performed to examine the function of the pancreas [28]. This is definitely meaningful, but its adaptation has declined in recent years.

As a substitute, studies by the meal tolerance test (MTT) are also performed in the clinical setting [29, 30]. MTT has been usually provided as breakfast. One of the standard MTT has $450 \mathrm{kcal}$ including 15\% protein, $35 \%$ fat, $50 \%$ carbohydrate, $1.6 \mathrm{~g}$ salt $[29,30]$. In this case, carbohydrate amount is calculated to be $56 \mathrm{~g}$ per breakfast.

This report is a joint study of the above two axes. As to the subjects, the background of 3 groups was almost equivalent, and the difference of $M$ value was larger than that of HbA1c. M value represents both average blood glucose level and mean amplitude of glycemic excursions (MAGE) [23, 24, 27]. The obtained numerical level of $\mathrm{M}$ value has always larger differences compared with that of HbA1c. Then, it seems to be useful as clinical research, for tracking one person and also for comparison with many cases.

Regarding our current data, fasting blood glucose in median showed similar levels in 3 groups (low, middle, high), and the data was rather scattered widely in high group. High group revealed lower tendency of fasting C-peptide and fasting ratio of $\mathrm{CP} /$ Glucose than other two groups. These results suggest that high group might has lower secretion of insulin, while low and middle group might include inhomogeneous cases with various pancreatic function.
For the correlation with fasting ratio of C-peptide/ glucose, $R^{2}$ value was $0.078,0.054,0.040$ in HbA1c, $M$ value, average blood glucose respectively. The former two showed significant correlation ( $p<0.05)$, and further evaluation would be necessary and expected for accumulation of cases in the future study.

As for the terminology of Fasting ratio of C-peptide/ glucose, there was formerly the C-peptide index (CPI) which has the same meaning. However, CPI might show misunderstanding of the index, because there were several research concerning C-peptide/glucose on $0 \mathrm{~min}, 30 \mathrm{~min}, 120 \mathrm{~min}$ and delta (incremental) value between $0-30 \mathrm{~min}$, as well as the index of multiplying Fasting C-peptide and fasting glucose [31, 32]. From these situation, Fasting ratio of C-peptide/Glucose will be used in this report.

There was a report that postprandial serum C-peptide to plasma glucose concentration ratio would be used for index of $\beta$-cell function [32]. Interestingly, there is a novel index using fasting C-peptide and fasting glucose values [33]. It is defined as Fasting C-peptide $\mathrm{x}$ fasting glucose $/ 20$ would be a simple and would be an effective index of insulin resistance better than HOMA-IR in Japanese patients with T2DM [33].

Predictors of the future insulin use were investigated among fasting ratio of C-peptide/glucose, body mass index, fasting glucose, C-peptide level [34]. As a result, these factors were strong predictors of future insulin use in T2DM. According to the results of fasting ratio of C-peptide /glucose, there were divided into 3 groups, which were 1.7, 1.0, 0.4 in group 1,2,3, respectively. The percentage of the patients with insulin treatment was $8 \%, 24 \%, 46 \%$, respectively [34]. Thus, fasting ratio of C-peptide/glucose would be useful for speculation of decreasing pancreas function and inducing insulin therapy in the future.

There is another clinical study for pediatric patients with T2DM [35]. The ratio of mean blood glucose / fasting blood glucose may represent beta cell function rather than $\mathrm{HbA1} \mathrm{c}$ and fructosamine. Its median value was 1.48 with $\mathrm{HbA1c} 7.9 \%$, while our value in this study is 1.24 with $\mathrm{HbA} 1 \mathrm{c} 7.9 \%$. Possible reason of the difference might be from age, secretion ability and resistance of insulin.

Another research showed the usefulness of fasting ratio of C-peptide/glucose. For clinical diagnosis of type 1 and 2 diabetes or for insulin treatment, three 
Investigation of Fasting Ratio of C-Peptide/Glucose and Related Markers in Diabetes

indexes would be used for judgement [36]. They are fasting C-peptide, fasting ratio of $\mathrm{C}$-peptide/glucose and HOMA-ßC-peptide-index. Thus, fasting ratio of C-peptide/glucose could be applicable clinical practice.

\section{ConCLUSION}

In summary, fasting ratio of C-peptide/glucose and related parameters were investigated in this study. The results suggest the clinical usefulness for predicting pancreatic function, and for beneficial application of diabetic clinical practice and research in the future.

\section{ACKNOWLEDGEMENT}

As for this report, some part was presented at annual conference of Japan Diabetes Society (JDS), Tokyo, 2018. The authors and colleagues appreciate all related staffs and patients for their understanding and cooperation.

\section{REFERENCES}

[1] Reaven GM (1988) Role of insulin resistance in human disease. Diabetes. 37(12):1595-607.

[2] Cornier MA, et al. (2008) The metabolic syndrome. Endocr Rev. 29(7):777-822.

[3] Mendonça FM, de Sousa FR, Barbosa AL, Martins SC, Araújo RL, et al. (2015) Metabolic syndrome and risk of cancer: which link? Metabolism. 64(2):182-9. doi: 10.1016/j. metabol.2014.10.008.

[4] Ojo O. 2016 An overview of diabetes and its complications. Diabetes Res Open J. 2(2): e4-e6. doi: 10.17140/DROJ-2-e005

[5] American Diabetes Association. (2017) Glycemic Targets. Sec. 6. In <i>Standards of Medical Care in Diabetes-2017. Diabetes Care 40(Suppl. 1);S48S56. doi: 10.2337/dc17-er07a.

[6] Jensen MD, Ryan DH, Apovian CM, et al. (2014) 2013 AHA/ACC/TOS guideline for the management of overweight and obesity in adults: a report of the American College of Cardiology/ American Heart Association Task Force on Practice Guidelines and The Obesity Society. Circulation 129(suppl 2):S102-38.

[7] International Diabetes Federation (IDF). (2015) Standards of Medical Care in Diabetes-2015. Diabetes Care 38: S 1-S94. doi.org/10.2337/ dc15-S001
[8] American College of Physicians. (2017) Clinical Guidelines and Recommendations. Web site. http:// www.acponline.org/clinical-information/guidelines.

[9] American Diabetes Association (2018) Pharmacologic Approaches to Glycemic Treatment: Standards of Medical Care in Diabetes-2018. Diabetes Care. 41(Suppl 1):S73S85. doi: 10.2337/dc18-S008

[10] Bernstein RK (1997) Dr. Bernstein's Diabetes Solution. Little, Brown and company, New York.

[11] Shai I, Schwarzfuchs D, Henkin Y, et al. (2008) Weight loss with a low-carbohydrate, Mediterranean, or low-fat diet. N. Engl. J. Med. 359: 229-241.

[12] Friedman AN, Ogden LG, Foster GD, Klein S, Stein R, Miller B, et al. (2012) Comparative effects of low-carbohydrate high-protein versus lowfat diets on the kidney. Clin J Am Soc Nephrol. 7:1103-11.

[13] Feinman RD, Pogozelski WK, Astrup A, Bernstein RK, Fine EJ, et al. (2015) Dietary carbohydrate restriction as the first approach in diabetes management: critical review and evidence base. Nutrition. 31(1):1-13. doi: 10.1016/j. nut.2014.06.011.

[14] Ebe K, Ebe Y, Yokota S, Matsumoto T, Hashimoto M, Sakai Y, et al. (2004) Low Carbohydrate diet (LCD) treated for three cases as diabetic diet therapy. Kyoto Medical Association Journal 51: 125-129.

[15] Bando H, Ebe K, Muneta T, Bando M, Yonei Y (2017) Clinical Effect of Low Carbohydrate Diet (LCD): Case Report. Diabetes Case Rep 2: 124. doi:10.4172/2572-5629.1000124

[16] Muneta T, Kawaguchi E, Nagai Y, Matsumoto M, Ebe K, Watanabe H, et al. (2016) Ketone body elevation in placenta, umbilical cord, newborn and mother in normal delivery. Glycative Stress Research 2016; 3 (3): 133-140. doi : 10.24659/ gsr.3.3_133

[17] Bando H, Ebe K, Muneta T, Bando M, Yonei Y (2017) Effect of low carbohydrate diet on type 2 diabetic patients and usefulness of M-value. Diabetes Res Open J. 2017; 3(1): 9-16. doi: 10.17140/DROJ-3-130. 
Investigation of Fasting Ratio of C-Peptide/Glucose and Related Markers in Diabetes

[18] Ebe K, Bando H, Muneta T, Bando M, Yonei Y (2017) Effect of low carbohydrate diet (LCD) for diabetic patients with hypertriglycemia. Endocrinol Metab. Vol. 1 No. 1:104.

[19] Bando H, Ebe K, Muneta T, Bando M, Yonei Y (2017) Proposal for Insulinogenic Index (IGI)Carbo70 as Experimental Evaluation for Diabetes . J Clin Exp Endocrinol 1: 102.

[20] Japan Diabetes Association (2013) Diabetes clinical practice guidelines Based on scientific evidence.

[21] Service FJ, Molnar GD, Rosevear JW, Ackerman E, Gatewood LC, et al. (1970) Mean amplitude of glycemic excursions, a measure of diabetic instability. Diabetes. 19: 644-655.

[22] MolnarGD, Taylor WF, Ho MM. (1972) Day-to-day variation of continuously monitored glycaemia: A further measure of diabetic instability. Diabetologia. 1972; 8(5): 342-348. doi: 10.1007/ BF01218495

[23] Moberg E, Kollind M, Lins PE, Adamson U (1993) Estimation of blood-glucose variability in patients with insulin-dependent diabetes mellitus. Scand J Clin Lab Invest. 53: 507-514

[24] McDonnellCM, Donath SM, Vidmar SI, Werther GA, Cameron FJ (2005) A novel approach to continuous glucose analysis utilizing glycemic variation. Diabetes Technol Ther. 7: 253-263. doi: 10.1089/dia.2005.7.253

[25] Yanai H (2015) Four step excel statistics, 4th Edition, Seiun-sha Publishing Co.Ltd, Tokyo.

[26] Bando H, Ebe K, Muneta T, Bando M, Yonei Y (2018) Urinary C-Peptide Excretion for Diabetic Treatment in Low Carbohydrate Diet (LCD). Journal of Obesity and Diabetes 1: 13-18.

[27] MonnierL, Colette C, Owens DR (2008) Glycemic variability: The third component of the dysglycemia in diabetes. Is it important? How to measure it? J Diabetes Sci Technol. 2(6):1094-1100.

[28] Bonora E, Zavaroni I, Alpi O, Pezzarossa A, Bruschi F, Guerra L, et al. (1986) Insulin and C-peptide responses to $75 \mathrm{~g}$ oral glucose load in the healthy man. Diabete Metab. 12(3):143-8.

[29] Yoshino G, Tominaga M, Hirano T, Shiba T, Kashiwagi A, et al. (2006) The test meal A:A pilot model for the international standard of test meal for an assessment of both postprandial hyperglycemia and hyperlipidemia. JJpn Diabetes Soc 49:361-371.

[30] Ohkura T, Shiochi H, Fujioka Y, Sumi K, Yamamoto $\mathrm{N}$, et al. (2013) 20/(fasting C-peptide $\times$ fasting plasma glucose) is a simple and effective index of insulin resistance in patients with type 2 diabetes mellitus: a preliminary report. Cardiovasc Diabetol. 12:21. doi: 10.1186/1475-2840-12-21.

[31] Iwata M, Maeda S, Kamura Y, Takano A, Kato H, et al. (2012) Genetic risk score constructed using 14 susceptibility alleles for type 2 diabetes is associated with the early onset ofdiabetes and may predict the future requirement of insulin injectionsamong Japanese individuals. Diabetes Care 35:1763-1770.

[32] Okuno Y, Komada H, Sakaguchi K, Nakamura T, Hashimoto N, Hirota Y, et al. (2013) Postprandial serum C-peptide to plasma glucose concentration ratio correlates with oral glucose tolerance testand glucose clamp-based disposition indexes. Metabolism. 62(10):1470-6. doi: 10.1016/j. metabol.2013.05.022.

[33] Ohkura T, Shiochi H, Fujioka Y, Sumi K, Yamamoto $\mathrm{N}$, et al. (2013) 20/(fasting C-peptide $\times$ fasting plasma glucose) is a simple and effective index of insulin resistance in patients with type 2 diabetes mellitus: a preliminary report. Cardiovasc Diabetol. 12:21. doi: 10.1186/1475-2840-12-21.

[34] Goto A, Takaichi M, Kishimoto M, Takahashi Y, Kajio H, et al. (2010) Body mass index, fasting plasma glucose levels, and C-peptide levels as predictors of the future insulin use in Japanese type 2 diabetic patients. Endocr J. 2010;57(3):237-44

[35] Lee JE, Lee JW, Fujii T, Fujii N, Choi JW (2014) The ratio of estimated average glucose to fasting plasma glucose level is superior to glycated albumin, hemoglobin A1c, fructosamine, and GA/ 
Investigation of Fasting Ratio of C-Peptide/Glucose and Related Markers in Diabetes

A1c ratio for assessing $\beta$-cell function in childhood diabetes. Biomed Res Int. 2014:370790. doi: 10.1155/2014/370790.

[36] Becht FS, Walther K, Martin E, Nauck MA (2016) Fasting C-peptide and Related Parameters
Characterizing Insulin Secretory Capacity for Correctly Classifying Diabetes Type and for Predicting Insulin Requirement in Patients with Type 2 Diabetes. Exp Clin Endocrinol Diabetes. 124(3):148-56. doi: 10.1055/s-0035-1565177.

Citation: Hiroshi BANDO, Koji EBE, Tetsuo MUNETA, Masahiro BANDO, Yoshikazu YONEI. Investigation of Fasting Ratio of C-Peptide/Glucose and Related Markers in Diabetes. Archives of Diabetes and Endocrine System. 2018; 1(1): 17-24.

Copyright: (C) 2018 Hiroshi BANDO, Koji EBE, Tetsuo MUNETA, Masahiro BAND0, Yoshikazu YONEI. This is an open access article distributed under the Creative Commons Attribution License, which permits unrestricted use, distribution, and reproduction in any medium, provided the original work is properly cited. 